\title{
Anotaciones para la agenda del bicentenario: desigualdad y mujer
}

\section{Annotations for the bicentennial agenda: inequality and women}

\author{
Carolina Mirian Lovón-Cueva \\ Universidad de Lima
}

\section{RESUMEN}

En los últimos años, la manifestación de la violencia de género ha trascendido, en algunos casos, límites de la insensibilidad e intolerancia humana a través de maltratos, humillaciones, exclusiones e, incluso, asesinatos. Esta violencia es causada por un sesgo cultural que apoya y resalta la jerarquía dominante; es decir, constituye reglas culturales, sociales y jurídicas que imponen patrones autoritarios; asimismo, implanta estereotipos e ideas para seguir dentro de una sociedad. En consecuencia, la configuración y difusión de estereotipos, la asignación de roles y funciones, entre otras, generan desigualdades, prejuicios, actos discriminatorios y violentos. Este artículo pretende informar sobre el origen y evolución de la violencia de género, ofrecer datos sobre la situación de dicha violencia en el Perú y describir las consecuencias ocasionadas por la violencia de género a través de una metodología descriptiva de los artículos originales de la Organización de las Naciones Unidas, del Ministerio de la Mujer y de las Poblaciones Vulnerables, y del Movimiento Manuela Ramos.

Palabras clave:

violencia de género, patriarcado, dominación, desigualdad, estereotipo

\section{ABSTRACT}

In recent years, expressions of gender violence have transcended, in some cases, the limits of human insensitivity and intolerance through mistreatment, humiliations, exclusions and even murders. This violence is caused by a cultural bias which supports and stands out the dominant hierarchy. That is to say, it establishes cultural, social and juridical rules that impose authoritarian patterns. Moreover, it sets up stereotypes and ideas to follow in a society. Consequently, the configuration and diffusion of stereotypes, the assignment of roles and functions, among other things, generate inequalities, prejudices, and discriminatory and violent behaviors. This article aims to give a report on the origin and evolution of gender violence, provide information about the situation of this specific violence in Peru, and describe its consequences through a descriptive methodology found in original articles of the United Nations, the Ministry of Women's Affairs and Vulnerable Populations, and the Manuela Ramos Movement.

\section{Keywords:}

gender violence, patriarchy, domination, inequality, stereotype 
1. Violencia de género: desigualdad en la sociedad contemporánea

D urante los últimos años, la violencia de género se ha convertido en una preocupación mundial debido al impacto social, económico, político, entre otros, lo que ha acrecentado la conciencia acerca de las desventajas de las mujeres en la sociedad. Se estima que los índices de violencia de género "van del 23,2 \% en los países de ingresos elevados y el 24,6 \% en los países de la Región del Pacífico Occidental al $37 \%$ en la Región del Mediterráneo Oriental y el 37,7 \% en la Región de Asia Sudoriental" (Organización Mundial de la Salud, 2016). En la región, Perú ocupa el primer puesto con un índice de $32,3 \%$ de violencia contra la mujer (Instituto Nacional de Estadística e Informática, 2014). Ello ha generado que se tomen medidas para reducir o erradicar esta problemática a partir de estudios sobre la igualdad de género.

La relación individuo-sociedad es una forma de relación significativa de poder porque establece diferencias jerárquicas de género, que divide en masculino y en femenino, subsumidas en relaciones de subordinación o de dominio. Esta violencia se ha sustentado en formas culturales que toleran la superioridad de los hombres sobre las mujeres como mecanismo de sometimiento para afianzar y ejercer su autoridad, lo que ha conducido a un impacto de desigualdades sociales.

\section{La humanidad se divide en categorías de géneros de individuos}

La categoría de género está constituida por el carácter histórico y social que distingue a los seres humanos según sus diferencias sexuales: masculino y femenino. De modo que, a partir de ello, se internalizan, mediante procesos de socialización o un conjunto de prácticas, estereotipos, roles, normas, actitudes, valores, entre otros, "imbuidas de contenidos sociales, que se transmiten, circulan y reproducen al interior de las mentalidades y de las instituciones sociales como parte fundante de la experiencia de vida y de la conformación de las identidades individuales y colectivas" (Cabral y García, 1991, p. 4). Es decir, el género designa un sistema clasificatorio de representación cultural acerca de los roles, identidades y valores que son atribuidos a varones y mujeres, y socializados sobre la base de la diferencia sexual o significación asignada al cuerpo sexuado. Entonces, se ha asumido el concepto de género como construcción social que condiciona la vida personal y social del varón y la mujer, lo que evidencia una conversión cultural en desigualdad' como dinámica propia del sistema social.

ElMovimiento Manuela Ramos(MMR), en Transversalidad de género (2013), define al género como

\begin{abstract}
una categoría de análisis que hace referencia a las relaciones de poder que se establecen entre mujeres y hombres; $y$ tiene que ver con los comportamientos, roles, posibilidades, oportunidades distintas a cada sexo, entre otros; es decir, determina las diferencias culturalmente establecidas y aceptadas, asignadas según las diferencias biológicas entre hombres y mujeres. A partir de estas variantes se estructura la manera de actuar en la vida social; empieza a adquirirse estructuras simbólicas de identidad, representaciones, actitudes, valores y normas. El género, por ser una construcción social y cultural, puede ser transformado. (p. 10)
\end{abstract}

Esto quiere decir que las diferencias, opresiones, jerarquías o exclusiones han justificado las desigualdades de género que determinan a los varones y a las mujeres de acuerdo a lo masculino y a lo femenino. Por lo tanto, el concepto de género es una categoría relacional porque se refiere a las relaciones entre la construcción social de mujeres y varones, que permite entender sus propios derechos.

El género como categoría de análisis posibilita la comprensión de las desigualdades entre hombres y mujeres, ya que supone un soporte teórico y crítico para reconocer las asignaciones sociales, los estereotipos o roles para cada sexo, lo cuales han sido establecidos por una lógica dominante o androcéntrica.

1 En este sentido, el concepto de desigualdad se construye social, cultural e históricamente; pero con apariencia natural, absoluta o universal. 


\section{Aproximación histórica de la categoría de género}

El término género apareció como contribución teórica en las ciencias sociales y en el discurso feminista, que lo concebía como una cualidad fundamental social de las distinciones basadas en el sexo. Según Izquierdo, desde el campo de las ciencias sociales, John Money y Robert Stoller, en 1955, investigaron sobre las conductas atribuidas a los varones y a las mujeres, y establecieron la diferencia conceptual entre sexo y género:

1 El sexo. Relativo a los aspectos anatómicos y fisiológicos, lo corporal. Que daría lugar básicamente a dos posibilidades: hembra y macho.

2. El género. Relativo a los aspectos psíquicos y sociales. Cuyas dos posibilidades serían: femenino, masculino.

Este planteamiento implicaría dividir a la mujer y al hombre en dos componentes, ser mujer u hombre sería el resultado de una adición:

$$
\begin{aligned}
& \text { Mujer = sexo hembra + género femenino } \\
& \text { Hombre = sexo macho + género masculino }
\end{aligned}
$$

Figura 1. Marco teórico de la igualdad.

Fuente: Izquierdo (s. f.).

Desde entonces, los estudios determinan que el género es constituido por un conjunto de roles, prácticas, actitudes, funciones, representaciones, identidades, normas y valores sociales, que construyen las sociedades a partir de la diferencia sexual anatómico-fisiológica.

Por otro lado, las teorías feministas, durante los años sesenta y setenta del siglo $\mathrm{xx}$, incorporaron la categoría de género desde un enfoque reflexión-acción; teorías que coinciden en que el género no se basa en un concepto natural, sino que se construye a partir de un proceso histórico-social. En ese sentido, la categoría de género se remite a un sistema de relaciones que se establecen entre los géneros masculino-femenino; por lo que rechaza todo determinismo biológico implícito en el empleo de términos tales como sexo o diferencia sexual. Según Eva Espinar (2007),

\begin{abstract}
el término género retoma, en su definición, ideas ya elaboradas por autores claves para la tradición filosófica feminista como, por ejemplo, Poulain de la Barre (De la igualdad de los dos sexos o La educación de las damas) en el siglo xvil, Olympe de Gouges (Declaración de los derechos de la mujer) y Mary Wollstonecraft (Vindicación de los derechos de la mujer) en el siglo xVIII, o John Stuart Mill (La esclavitud de la mujer) en el siglo xIx. (p. 25)
\end{abstract}

Posteriormente, en 1949, Simone de Beauvoir afirmaría que "una mujer no nace sino que se hace" (como se citó en Espinar, 2007, p. 25), lo que quiere decir que la mujer no se construye sobre la base de determinaciones biológicas; por el contrario, las funciones, comportamientos y atributos de cada sociedad constituyen a la mujer. A partir de estas declaraciones, se sistematizaría el término género como discurso propio y específico para repensar, redefinir y representar a la mujer en un marco de perspectiva de género, en los años ochenta del siglo xx.

Por lo tanto, la categoría de género alude a las relaciones de género en tanto vínculos de conducta, lo cual descarta la relación natural de lo femenino y masculino, o a su sexo. De este modo, la acepción generalizada de la categoría de género como construcción social se contrapone a la dinámica social proyectiva ${ }^{2}$. Este mecanismo social corresponde a un sistema de poder acompañado de discursos hegemónicos; donde se evidencian conflictos sociales, tales como las desigualdades sociales, políticas, económicas, culturales, entre varón y mujer.

Muchos países de la región, en la actualidad, ejercen la imposición discursiva hegemónica y las actitudes dominantes sobre la población femenina.

2 Este concepto alude al mecanismo de fluidez de las costumbres y creencias que rigen la conducta de los individuos en el transcurso de la experiencia social, con una visión de proyección o hacia el futuro. 


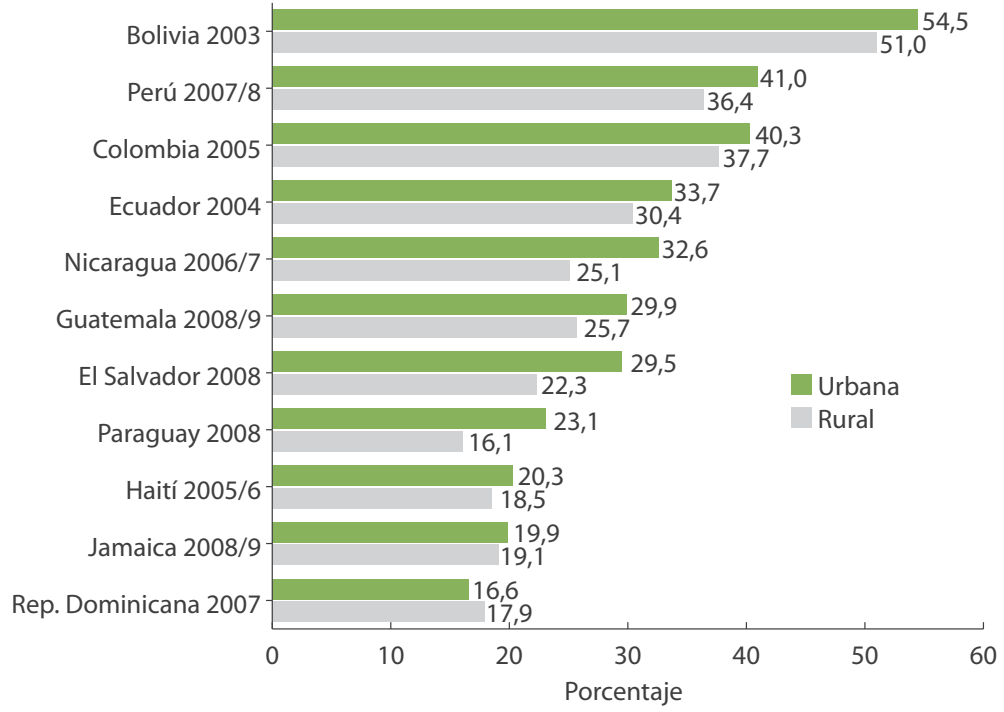

Figura 2. Prevalencia de violencia por parte de un esposo/compañero alguna vez, según residencia urbana o rural

Fuente: OPS, 2014

\begin{tabular}{|c|c|c|c|c|c|c|c|}
\hline & \multirow{2}{*}{\begin{tabular}{|} 
Actos moderados, \\
alguna vez \\
Abofetearla, \\
sacudirla, \\
arrojarle objetos, \\
empujarla, \\
arrastrala, \\
torcerle un brazo, \\
jalarle el pelo \\
\end{tabular}} & \multicolumn{5}{|c|}{ Actos graves, alguna vez } & \multirow[b]{2}{*}{ Total } \\
\hline & & $\begin{array}{c}\text { Pegarle con } \\
\text { un puño o con } \\
\text { un objeto que } \\
\text { podría causarle } \\
\text { daño }\end{array}$ & $\begin{array}{c}\text { Patearla, } \\
\text { arrastrala } \\
\text { o golpearla }\end{array}$ & $\begin{array}{c}\text { Intentar } \\
\text { asfixiarla } \\
\text { o quemarla }\end{array}$ & $\begin{array}{l}\text { Amenazarla o } \\
\text { herirla con un } \\
\text { cuchillo, } \\
\text { un arma } \\
\text { de fuego u otro } \\
\text { tipo de arma }\end{array}$ & $\begin{array}{c}\text { Cualquier acto } \\
\text { de violencia } \\
\text { grave }\end{array}$ & \\
\hline & $\%$ & $\%$ & $\%$ & $\%$ & $\%$ & $\%$ & $\begin{array}{c}\text { Número } \\
\text { (no ponderado) }\end{array}$ \\
\hline Encuestas DHS & \multicolumn{7}{|c|}{ Por parte del esposo/compañero actual o más reciente solamente: } \\
\hline Bolivia 2003 & ND & 11,3 & ND & 8,2 & ND & ND & 12054 \\
\hline Colombia 2005 & 37,9 & 9,5 & 13,7 & 5,1 & 8,3 & 19,4 & 25620 \\
\hline Haití 2005/6 & 12,5 & 6,2 & 3,7 & 2,2 & 2,1 & 7,4 & 2680 \\
\hline Perú 2007/8 & 35,5 & 21,9 & 16,3 & 4,1 & 3,6 & 25,5 & 12572 \\
\hline $\begin{array}{l}\text { Rep. Dominicana } \\
2007\end{array}$ & 15,4 & 8,1 & 3,3 & 2,6 & 3,6 & 9,6 & 8438 \\
\hline Encuestras RHS & \multicolumn{7}{|c|}{ Por parte de cualquier esposo/compañero actual o anterior: } \\
\hline Ecuador 2004 & 27,4 & 18,3 & & , 3 & 7,9 & 21,3 & 7217 \\
\hline El Salvador 2008 & 21,9 & 14,9 & 8,6 & 5,2 & 6,5 & 17,6 & 7349 \\
\hline $\begin{array}{l}\text { Guatemala } \\
\text { 2008/9 }\end{array}$ & 22,0 & 15,4 & 10,4 & 4,1 & 4,9 & 17,7 & 12768 \\
\hline Jamaica 2008/9 & 14,9 & 11,7 & 6,0 & 3,1 & 4,3 & 13,3 & 7222 \\
\hline Nicaragua 2006/7 & 24,8 & 19,2 & 11,3 & 7,3 & 7,8 & 21,3 & 11393 \\
\hline Paraguay 2008 & 16,7 & 9,3 & 6,2 & 4,2 & 4,7 & 11,7 & 4414 \\
\hline
\end{tabular}

Figura 3. Porcentaje de mujeres que informaron violencia física por parte de un esposo/compañero alguna vez, por acto, entre las mujeres de 15 a 49 años

Fuente: OPS, 2014 


\section{4. ¿Qué es violencia de género? Modelos perpetuos desde la perspectiva de género}

En el siglo XVIII, la representación opresiva de la mujer fue muy marcada a partir de los pensamientos ideológicos de la llustración y la filosofía moderna, ya que construyeron la identidad subordinada de la mujer en espacios sociales y políticos, desde la diferencia sexual entre varones y mujeres. La construcción diferencial ha generado dicotomías biológicas y sociales que justifican las desigualdades de géneros en relaciones jerárquicas, de exclusión, de opresión, o de oposición, dentro de un patrón dominante que define al varón y a la mujer según lo establecido por un orden social.

Este proceso ha constituido un mecanismo de contribución a la hegemonía del varón, con modelos de socialización circunscritos desde la clase social, la religión, etcétera, los cuales demarcan la vida personal y social. También, el género como categoría conceptual contiene una exclusión entre las relaciones de los géneros, porque conviven en un sistema social que les designan roles, identidades y funciones estereotipados, reproducidos y legitimados mediante dispositivos de poder, tales como creencias, costumbres, valores, prácticas sociales, filosofías, discursos, ideologías y leyes, aquellos que contribuyen a la subordinación de los géneros basados en un modelo androcéntrico.

Entonces, este sistema social convierte las diferencias sexuales en diferencias sociales, que son respaldadas por una lógica de poder asimétrica de relaciones de dominación y exclusión por medio de condiciones sociohistóricas. Con ello, la categoría de género se complejiza hacia una categoría de análisis de las desigualdades y de las prácticas sociales desde un marco teóricoreflexivo, que busca visibilizar las desigualdades sociales a través de la deconstrucción del modelo hegemónico del patriarcado o de la desnaturalización de las prácticas socioculturales establecidas. De manera que los estudios de género, desde una perspectiva de género, investigan, cuestionan, visibilizan y desestructuran las diferencias naturales-culturales, las asimetrías de género, los estereotipos, los discursos de poder, etcétera, que han sido legitimados como universales por el pensamiento de la llustración y la filosofía moderna.

De esta manera, la perspectiva de género tiende a deconstruir el orden jerárquico androcéntrico o dominación masculina que asigna comportamientos fijos e inmutables para cada sexo; por lo que redefine tanto a la mujer y al varón como individuos de un sistema social más allá de las brechas de género. Por ello, el avance de la perspectiva de género visibiliza los conflictos de las relaciones basados en género, que estaban confinados a una esfera privada, hacia un asunto social y político que denuncia y cuestiona toda forma de dominación de estructura patriarcal.

De tal modo, el aumento de las desventajas en las representaciones sociales entre el varón y la mujer genera consciencia de este problema. Por ejemplo, el índice de desigualdad de género estima las condiciones de desventajas en las que se encuentra la mujer. En el caso de Perú, el índice de desigualdad revela la pérdida de logros en las dimensiones de salud reproductiva, empoderamiento y mercado laboral, en relación con la desigualdad de género, para comprender las brechas y diferencias entre mujeres y varones. Por ello, la perspectiva de género incentiva, a partir de un seguimiento de propuestas u objetivos, hacia el progreso de la equidad de género (INEI, 2016, p. 26).

Las desigualdades e injusticias entre varones y mujeres fomentan la violencia de género. Esta es definida por la Organización de Naciones Unidas (ONU) al considerar que "toda persona puede ser víctima de actos de violencia, pero el sexo se convierte en uno de los factores que aumenta de modo significativo su vulnerabilidad" (como se citó en INEl, 2014, p. 467)33. Por ende, es esencial identificar y medir las desventajas que enfrentan las mujeres con la finalidad de concientizar e impulsar alternativas para generar la equidad de género.

Las desigualdades de género ocasionan violencia de género; al respecto, María Luisa Maqueda (2006) señala:

3 Para María Luisa Maqueda (2006): “Es significativo que hasta muy avanzado el siglo pasado no se encuentre ninguna referencia precisa a esa forma específica de violencia en los textos internacionales, salvo acaso como expresión indeterminada de una de las formas de discriminación contra la mujer proscrita por la Convención de Naciones Unidas de 1979. Sólo a partir de los años noventa, comienza a consolidarse su empleo gracias a iniciativas importantes tales como la Conferencia Mundial para los Derechos Humanos celebrada en Viena en 1993, la Declaración de Naciones Unidas sobre la eliminación de la violencia contra la mujer del mismo año, la Convención Interamericana para prevenir, sancionar y erradicar la violencia contra la mujer (1994) o la Conferencia Mundial de Mujeres de Beijing (1995)" (p. 2). 
Se trata de una variable teórica esencial para comprender que no es la diferencia entre sexos la razón del antagonismo, que no nos hallamos ante una forma de violencia individual que se ejerce en el ámbito familiar o de pareja por quien ostenta una posición de superioridad física (hombre) sobre el sexo más débil (mujer), sino que es consecuencia de una situación de discriminación intemporal que tiene su origen en una estructura social de naturaleza patriarcal. El género se constituye así en el resultado de un proceso de construcción social mediante el que se adjudican simbólicamente las expectativas y valores que cada cultura atribuye a sus varones y mujeres. Fruto de ese aprendizaje cultural de signo machista, unos y otras exhiben los roles e identidades que le han sido asignados bajo la etiqueta del género. De ahí, la prepotencia de lo masculino y la subalternidad de lo femenino. Son los ingredientes esenciales de ese orden simbólico que define las relaciones de poder de los hombres sobre las mujeres, origen de la violencia de género ${ }^{4}$. (p. 2)

Finalmente, la violencia de género es el acto dirigido hacia las mujeres, sin exclusión de edad, que ocasiona un daño físico, psicológico o sexual, y tiene lugar en la atmósfera pública, como el hogar, la calle, el trabajo, el centro de estudios, instituciones privadas o públicas, y en la atmósfera privada, al interior de sus hogares o en relaciones interpersonales, donde, a pesar de las denuncias, los casos de violencia de género quedan impunes. Esta violencia"puede ser ejercida por la pareja, un familiar, un desconocido, un funcionario público o un agente del Estado, como fue la violencia ocurrida en el contexto del conflicto armado interno que afectó de manera especial a las mujeres" (MMR, 2011, p. 9). En el Perú, entre 1980 y 2000, se vivió el conflicto armado interno, en el que se vulneró los derechos de las mujeres, grupo más afectado por crímenes de violencia sexual. El Ministerio de la Mujer y Poblaciones Vulnerables (MIMP) (2016) señala:

la violación sexual, el embarazo forzado y el aborto forzado fueron las principales formas en las que se dio esta modalidad de violencia. En el Informe de la Comisión de la Verdad y la Reconciliación se informó que el $99 \%$ de los casos de violación fueron de mujeres, lo que indica que se estaba claramente ante una violencia de género. Asimismo, la violación representa claramente la forma de agresión criminal y de afectación de derechos más frecuente entre las mujeres en los casos reportados por la Comisión. (p. 36)

\section{Razones que desvelan la violencia de género}

La violencia de género es un problema social que involucra a mujeres de "distintas culturas, condiciones sociales, niveles de educación, religión, raza, etnia y edad, producto de una organización estructurada en relaciones de poder históricamente desiguales entre mujeres y varones, que responden a patrones sociales y culturales profundamente arraigados en la sociedad" (INEl, 2014, p. 467). En otros términos, las razones de la violencia de género se han legitimado en la sociedad por la desigualdad y discriminación garantizadas por la posición hegemónica masculina para mantener un orden tradicional.

La violencia de género es de naturaleza multicausal, así su impacto y carácter varían según ciertos factores, "como la etnia, la clase social, la preferencia sexual, las discapacidades y las afiliaciones políticas y religiosas, que inciden en la victimización de la población femenina" (Rico, 1996, p. 8). Es decir, la violencia de género es de carácter estructural porque se sostiene en elementos socioculturales que definen identidades, atributos, roles y relaciones sociales en función al sexo; los cuales, a su vez, refuerzan, reproducen y perpetúan un orden social desigual y discriminatorio, pues sus raíces están reflejadas, principalmente, en las relaciones sociales de dominación androcéntrica. Aquella que se enmarca en la lógica del patriarcado, supremacía de lo masculino sobre lo femenino, ideología que determina un conjunto de prácticas sociales asimétricas entre varones y mujeres. Este sistema socializador niega los derechos de las mujeres y propaga la inequidad entre los géneros y sexos, al conferirle un rol de poder y dominación al varón sobre la mujer; por lo que dicha resistencia ideológica dificulta el goce de derechos vigentes de las mujeres en la sociedad 5 .

4 La Convención Belém do Pará identifica a la violencia de género independiente de la violencia doméstica, ya que se concentra en la violencia ejercida por los valores tradicionales de la autoridad masculina.

5 Desde la década de los noventa, se ha logrado un cambio significativo contra la violencia de género: "a través de las recomendaciones de la Convención sobre la Eliminación de Todas las Formas de Discriminación contra la Mujer (CEDAW) y la Convención para Prevenir, Sancionar y Erradicar la Violencia contra la Mujer (Convención de Belem do Pará); las Plataformas y Programas de Acción de las Conferencias Mundiales, entre ellas la de Viena sobre Derechos Humanos, la de El Cairo, sobre Población, y especialmente, la IV Conferencia de la Mujer en Beijing, en 1995; las Declaraciones sobre la Eliminación de la Violencia contra la Mujer del año 1993; los instrumentos de la Organización Panamericana de la Salud, que incorporaron la violencia como tema prioritario al considerarla una causa significativa de las enfermedades de las mujeres; y las Relatorías Especiales sobre violencia 
Otras de las prácticas que generan violencia de género son la división sexual del trabajo y la construcción de identidades de género desiguales. Estas se caracterizan por...

las condiciones socioculturles que la generan; por una parte, la división sexual del trabajo y, por otra, aspectos ideológico-culturales adquiridos en el proceso de socialización diferencial y en el aprendizaje cotidiano de los roles y atributos psíquicos estereotipados que se otorgan a varones y mujeres y que, una vez introyectados en sus identidades crean condiciones que contribuyen a la violencia. (Rico, 1996, p. 19)

En la división sexual del trabajo, las mujeres enfren$\tan$ discriminaciones y desigualdades en el ejercicio de sus derechos económicos y políticos, lo que da lugar a oportunidades reducidas o limitadas al ámbito laboral, al mercado de trabajo, a la educación, a la seguridad política, a la asistencia sanitaria, etcétera. En la construcción de identidades de géneros desiguales, se interiorizan rasgos, roles, estereotipos diferenciales asociados al sexo (biología) a través de la familia, la escuela, la religión o los medios de comunicación, para normalizar o naturalizar comportamientos tradicionales que atentan contra la dignidad e integridad de la mujer, privándolas de su condición de sujeto de derechos; ya sea al estereotipar a la mujer como objeto sexual o ama de casa, o al reconocer que solo el varón tiene carácter agresivo por su condición masculina.

Por lo tanto, es necesario analizar el conjunto de creencias, normas y prácticas sociales que legitiman los comportamientos abusivos o violentos, justificados en valores de dominación, sumisión y desigualdad, para aplicar medidas que eviten la vulneración de derechos.

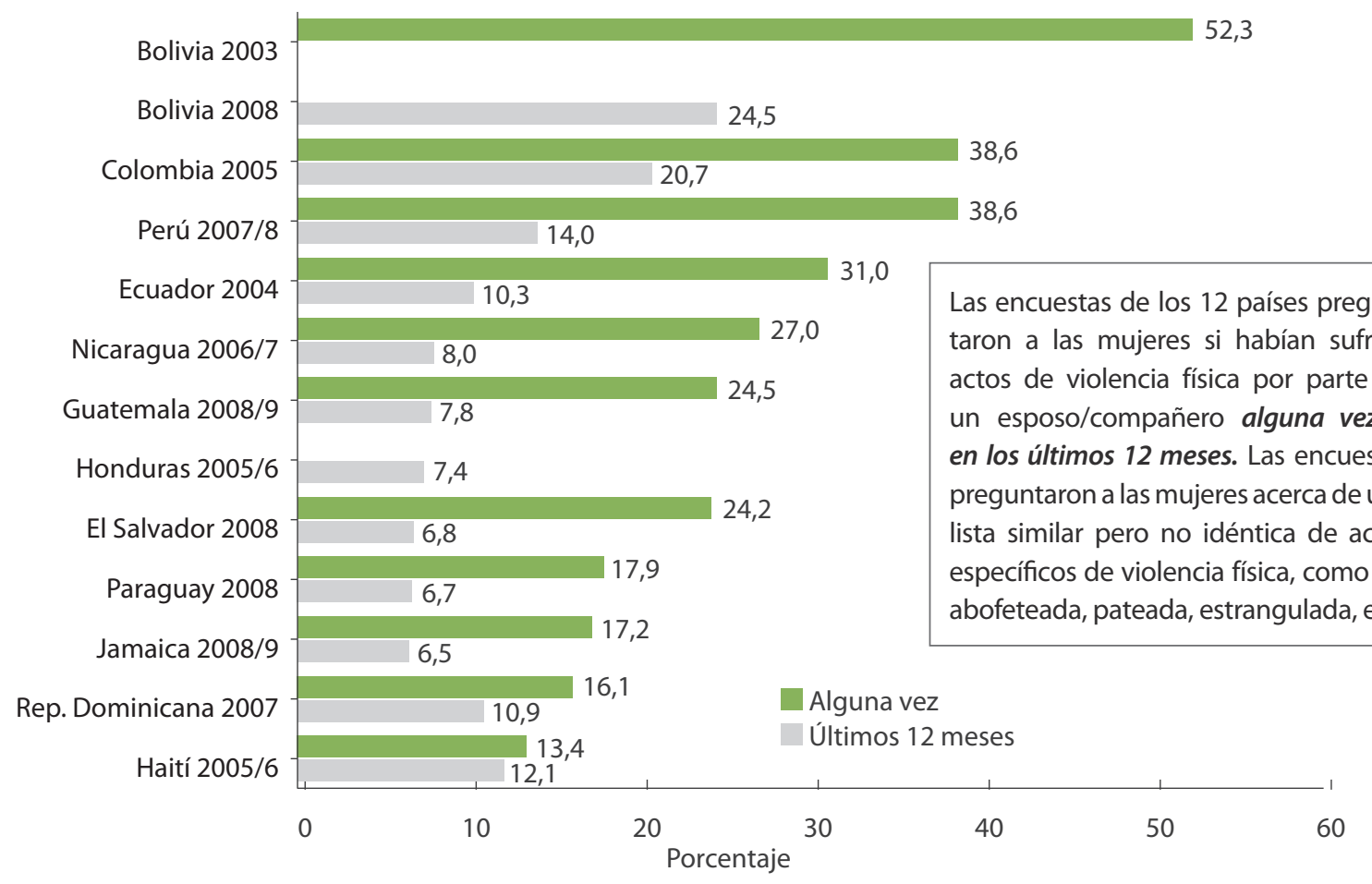

Figura 4. Porcentaje de mujeres que informaron violencia física por parte de un esposo/compañero, alguna vez y en los últimos 12 meses, entre 15 a 49 años.

Fuente: OPS, 2014

y derechos humanos de las mujeres. Asimismo, los países de lberoamérica han establecido leyes y programas contra la violencia hacia las mujeres, tribunales y comisarías especializadas. Además, en ellos existen amplios movimientos, redes feministas y de mujeres que hacen de la lucha contra la violencia, su principal objetivo" (INEI, 2014, 467-468). 


\section{Impacto social de la violencia contra la mujer}

Las múltiples formas de violencia de género atentan contra los derechos de las mujeres y ocasionan graves consecuencias, como daños físicos, psicológicos o feminicidio. La dominación masculina ejerce control social de lo femenino y legitima el derecho de poder, por lo que la violencia de género afecta a la libertad y los derechos humanos, tales como:

El derecho a la identidad, puesto que refuerza y reproduce la subordinación de las mujeres a los varones, así como la distorsión del ser humano. La violencia también va contra el derecho al afecto, debido a que la violencia es la antítesis de toda manifestación de esa índole; del derecho a la paz $y$ a relaciones personales enriquecedoras, ya que es una forma negativa de resolución de conflictos; del derecho a la protección, debido a que crea una situación de desamparo, que no proviene solo del esposo y la familia, sino también del Estado, que niega protección a las mujeres, y de la sociedad que invisibiliza el problema. La violencia de género viola también el derecho al desarrollo personal, puesto que las víctimas sufren una parálisis psicológica que les impide desarrollar su potencial creativo; del derecho a la participación social y política, debido a que coarta la realización de actividades extradomésticas (con excepción de las mínimas relacionadas con los roles tradicionales), como la participación en organizaciones, grupos o reuniones; del derecho a la libertad de expresión, y del derecho a una salud física y mental óptima. (Como se citó en MIMP, 2012, p. 15)

Por su efecto, la violencia de género invisibiliza, oculta o niega los derechos de la mujer; las vulnera desde los diferentes entornos socioculturales dominantes e impide el goce de sus derechos fundamentales, como el derecho a la vida y a la seguridad personal, a la educación, al trabajo, a la vivienda, a la participación pública, etcétera.

Por un lado, la violencia de género tiene consecuencias para la salud y el bienestar de las mujeres. En primer lugar, las conductas aprendidas y reproducidas en las relaciones de poder entre varones y mujeres perjudican la salud de las mujeres. Las mujeres que son víctimas de abusos físicos (letales) y psíquicos tienden a un bajo funcionamiento social y en materia de salud mental. Las primeras desarrollan lesiones físicas con secuelas permanentes y las segundas presentan pérdida de autoestima, dificultades de concentración, síntomas depresivos, ansiedad, trastornos por estrés postraumático, ideación suicida, tendencia al alcohol, etcétera.

\begin{abstract}
Por ejemplo, un estudio realizado en Michigan (Estados Unidos) comprobó que el $59 \%$ de las mujeres que habían sufrido abusos graves en los 12 meses anteriores tenían problemas psicológicos, en comparación con el $20 \%$ de las que no habían declarado abusos. (ONU, 2006, p. 61)
\end{abstract}

Asimismo, la violencia extrema o letal produce feminicidio. En el Perú, el feminicidio...
registró un total de 795 feminicidios a nivel nacional (datos a octubre 2015) lo que significa un promedio de 113 feminicidios al año y 9 mujeres que mueren cada mes por el hecho de ser mujeres, según un consolidado de los datos de los años 2009 al 2015 del Ministerio Público. (MIMP, 2012, p. 30)

Por otra parte, existen pocos estudios que determinan la mortalidad materna y las muertes relacionadas al sida con las distintas formas de violencia de género. Según la Organización de las Naciones Unidas (2006),

\begin{abstract}
algunos estudios provenientes de los servicios de salud indican cierta relación entre la violencia infligida por la pareja y la muerte durante el embarazo. Por ejemplo, un estudio de 400 aldeas y siete hospitales de las zonas rurales de la India occidental comprobó que el $16 \%$ del total de muertes durante el embarazo eran resultado de violencia infligida por la pareja. Se ha encontrado una tendencia análoga en Bangladesh y en los Estados Unidos. (p. 59)
\end{abstract}

En consecuencia, existen varios efectos para la salud ocasionados por la violencia contra la mujer (figura 5).

En el Perú6, los índices de violencia de género son elevados en comparación con los de otros países. El MIMP registra:

según el Estudio Multicéntrico de la Organización Mundial de la Salud sobre violencia contra la mujer de parte de su pareja realizado el año 2000 (en el cual participaron 10 países del mundo), el departamento de Cusco se ubicó en el primer lugar en violencia física contra la mujer de parte de su pareja con $61 \%$, mientras que Lima Metropolitana compartió junto con la zona rural de Etiopía el segundo lugar con $49 \%$. (OMS, 2016, p. 28)

6 Véase cuadro estadístico de INEI (2014) sobre casos de violencia familiar y sexual registrados por el MIMP, según sexo y departamento. 


\section{) \\ Consecuencias en la salud de las mujeres}

La Organización Mundial de la Salud señala que la violencia de género es un grave problema de salud pública.
Son diversas las señales físicas psíquicas y sociales que se manifiestan en las mujeres por causa de la violencia intrafamiliar. Obviamente hay una afección directa sobre la salud de las mujeres. Algunas de estas señales que evidencian el haber padecido algún tipo de violencia se listan a continuación:

\begin{tabular}{|c|c|}
\hline Fatales & $\begin{array}{l}\text { - Muerte por homicidio } \\
\text { - Muerte por suicidio }\end{array}$ \\
\hline Salud física & $\begin{array}{l}\text { - Lesiones diversas: contusiones, traumatismos, heridas, quemaduras... que pueden producir discapacidad } \\
\text { - Deterioro funcional } \\
\text { - Síntomas físicos no específicos (cefaleas) } \\
\text { - Empeoramiento de la salud }\end{array}$ \\
\hline $\begin{array}{c}\text { Condiciones } \\
\text { crónicas de } \\
\text { la salud }\end{array}$ & $\begin{array}{l}\text { - Dolor crónico } \\
\text { - Síndrome del intestino irritable } \\
\text { - Otros transtornos gastrointestinales } \\
\text { - Quejas somáticas }\end{array}$ \\
\hline $\begin{array}{r}\text { Salud } \\
\text { sexualy } \\
\text { reproductiva }\end{array}$ & $\begin{array}{l}\text { - Por relaciones sexuales forzadas: Perdida de deseo sexual, transtornos menstruales, enfermedades de } \\
\text { transmión sexual, sífiles, gonorrea, clamidhia, virus papiloma humano (vinculado al cáncer cérvico uterino). } \\
\text { Hepatitis B. incluído el VIH / SIDA sangrado y fibrosis vaginal, dispareunia, dolor pélvico crónico, infección } \\
\text { urinaria, embarazo no deseado (que pueden terminar en abortos clandestinos). } \\
\text { - Por maltrato durante el embarazo: hemorragia vaginal, amenaza de aborto, muerte fetal, parto prematuro, } \\
\text { bajo peso al nacer. }\end{array}$ \\
\hline $\begin{array}{r}\text { Salud } \\
\text { psíquica }\end{array}$ & $\begin{array}{l}\text { - Depresión, ansiedad, baja autoestima, labilidad emocional } \\
\text { - Transtornos del sueño } \\
\text { - Transtorno por estrés postraumático } \\
\text { - Transtorno de la conducta alimentaria } \\
\text { - Abuso de alcohol, drogas y psicofármacos } \\
\text { - Intento de suicidio } \\
\text { - Estado emocional negativo (tristeza, miedo a morir, ideas suicidas, ansiedad extrema }\end{array}$ \\
\hline $\begin{array}{l}\text { Salud } \\
\text { Social }\end{array}$ & $\begin{array}{l}\text { - Aislamiento social, falta de redes sociales, escasa o nula participación en la comunidad, ausencia de contacto } \\
\text { con familiares } \\
\text { - Pérdida del empleo } \\
\text { - Absentismo laboral } \\
\text { - Disminución del número de días de vida saludable }\end{array}$ \\
\hline Relacionales & $\begin{array}{l}\text { - Control de las actividades cotidianas de la mujer, sumisión de parte de la mujer, prohibición de parte de la pareja } \\
\text { de salir, de trabajar y/o participar socialmente, la presencia de estereotipos de género tradicionales y rígidos }\end{array}$ \\
\hline $\begin{array}{l}\text { Actitud } \\
\text { de la víctima }\end{array}$ & $\begin{array}{l}\text { Temor, nerviosismo, ausencia de contacto visual, inquietud, sobresalto al menor ruído, ensimismamiento, tenden- } \\
\text { cia a culpabilizarse y a exculpar a su pareja, reticencia a responder preguntas o a dejarse explorar, incapacidad } \\
\text { para tomar decisiones }\end{array}$ \\
\hline
\end{tabular}

Figura 5. Consecuencias en la salud de las mujeres

Fuente: MIMP, 2012, p. 29

En segundo lugar, la violencia de género en los hogares afecta a los hijos, como víctimas o testigos, les imposibilita un desarrollo interpersonal y fragmenta el sentimiento de seguridad. Este tipo de violencia origina sentimientos de desesperanza, estrés, ansiedad, depresión, baja autoestima y otros problemas similares que pueden desencadenar diferentes trastornos psicológicos.

Por último, existe un impacto social de la violencia de género que no solo afecta la vida de las víctimas, sino que obstaculiza el desarrollo del país en sus diferentes sectores; ya que reduce la capacidad de la víctima en la contribución productiva a la familia, a la economía, a la educación, e inversión pública; además, la víctima requiere del acceso de servicios públicos, como el sistema judicial y de salud.

Por ello, es vital entender el problema de la violencia de género como un medio de control social sobre las mujeres y de reacción masculina que afecta a la sociedad en general, con la finalidad de evidenciar la incidencia económica en el Estado. Primero, los costos 


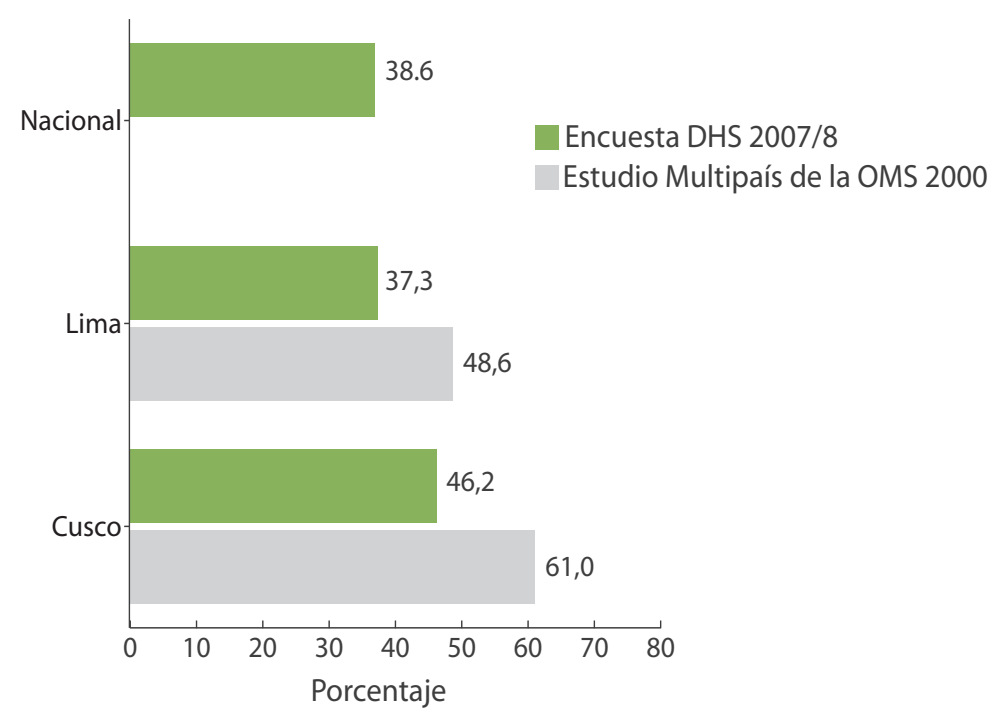

Figura 6. Porcentaje de mujeres del Perú que informaron violencia física por parte de una pareja alguna vez, por zona geográfica, entre las mujeres de 15 a 49 años, alguna vez casadas o unidas, en encuestas DHS y de la OMS.

Fuente: OPS, 2014

económicos directos aluden al servicio de la salud física y psicológica, al servicio judicial y social destinados a la víctima. Segundo, los costos económicos indirectos se refieren a la reducción de la productividad y pérdida de empleo por aquellas mujeres que han experimentado y experimentan violencia, ya que se ausentan de este por lesiones físicas o agresiones verbales de sus victimarios. En tal sentido, se evidencia un menor aporte a la sociedad por parte de las mujeres que reciben violencia, debido a que disminuirá el potencial de percibir su remuneración por diferentes aspectos: incapacidad laboral, estrés, ansiedad, depresión, lesiones letales, etcétera. En este caso, los empleadores son los responsables de cubrir los costos por licencias, capacitaciones de reemplazo, nuevas contrataciones, entre otros conceptos, lo que indica una pérdida de producción y costos adicionales ${ }^{7}$.

En síntesis, la violencia de género reduce el desarrollo económico del país, lo cual demuestra que se deben adoptar medidas preventivas y sostenidas. El INEI (2014) determina que

$$
\begin{aligned}
& \text { las principales manifestaciones de violencia contra la } \\
& \text { mujer son: las lesiones personales, el abuso y acoso } \\
& \text { sexual, la prostitución, la violación, el secuestro, la } \\
& \text { trata de personas, la tortura, la muerte violenta y } \\
& \text { las diversas formas de discriminación (exclusión o } \\
& \text { limitación contra la mujer por razón del género) } \\
& \text { que afectan y menoscaban el reconocimiento y el } \\
& \text { ejercicio legítimo de sus derechos. La violencia de } \\
& \text { género también afecta directamente a las niñas: son } \\
& \text { víctimas de la selección prenatal del sexo, los abortos } \\
& \text { forzados y el infanticidio. (pp. 467-468) }
\end{aligned}
$$

En este sentido, las mujeres se encuentran en una condición de vulnerabilidad por las diferentes manifestaciones de violencia, las cuales han surgido del pensamiento ideológico patriarcal. Este modelo concentra un orden social en el que los principios, funciones, normas y valores están direccionados por la identidad del varón.

7 Existen otros costos de la violencia contra la mujer reconocidos por la ONU (2006, p. 65). 


\begin{tabular}{|c|c|c|c|c|c|c|c|}
\hline & \multicolumn{2}{|c|}{ Violencia física } & \multicolumn{2}{|c|}{ Violencia sexual } & \multicolumn{2}{|c|}{$\begin{array}{c}\text { Violencia física o sexual } \\
\text { o ambas }\end{array}$} & \multirow{2}{*}{$\begin{array}{c}\text { Total: } \\
\text { mujeres alguna } \\
\text { vez } \\
\text { en pareja }\end{array}$} \\
\hline & Alguna vez & $\begin{array}{l}\text { Últimos } 12 \\
\text { meses }\end{array}$ & Alguna vez & $\begin{array}{l}\text { Últimos } 12 \\
\text { meses }\end{array}$ & Alguna vez & $\begin{array}{l}\text { Últimos } 12 \\
\text { meses }\end{array}$ & \\
\hline Encuestas de la OMS & $\%$ & $\%$ & $\%$ & $\%$ & $\%$ & $\%$ & $\begin{array}{c}\text { Número } \\
\text { (no ponderado) }\end{array}$ \\
\hline San Pablo, Brasil 2000/1 & 27,2 & 8,3 & 10,1 & 2,8 & 28,9 & 9,3 & 940 \\
\hline Pernambuco, Brasil 2000/1 & 33,8 & 12,9 & 14,3 & 5,6 & 36,9 & 14,8 & 1188 \\
\hline Lima, Perú 2000 & 48,6 & 16,9 & 22,5 & 7,1 & 51,2 & 19,2 & 1086 \\
\hline $\begin{array}{l}\text { Departamento de Cusco, } \\
\text { Perú } 2000\end{array}$ & 61,0 & 24,8 & 46,7 & 22,9 & 69,0 & 34,2 & 1535 \\
\hline
\end{tabular}

Figura 7. Resultados del estudio multipaís de la OMS correspondientes a América Latina: porcentaje de mujeres que informaron violencia por parte de la pareja alguna vez en la vida y en los últimos 12 meses, según tipo de violencia, entre 15 a 49 años.

Fuente: OPS, 2014

\section{Referencias}

CABRAL, B., y GARCíA, C. (1997). El género. Una categoría de análisis crítico para repensar las relaciones sociales entre los sexos. Recuperado de http://www.saber.ula.ve/bitstream/123456789/16344/1/genero-categoria.pdf

EsPINAR R., E. (2007). Las raíces socioculturales de la violencia de género. Escuela abierta. (10), 23-48. Recuperado de https://rua.ua.es/dspace/bitstream/10045/12973/1/Espinar_Ruiz_Raices_socioculturales.pdf

Instituto Nacional de Estadistica e Informática (INEI). (2014). Perú: Brechas de Género, 2001-2013. Avances hacia la igualdad de mujeres y hombres. Lima: Biblioteca Nacional del Perú.

Instituto NaCional de Estadística e Informática (INEI). (2016). Casos registrados de violencia familiar y sexual por el Ministerio de la Mujer y Poblaciones Vulnerables, según grupo de edad y departamento. Recuperado de https://www.inei.gob.pe/estadisticas/indice-tematico/brechas-de-genero-7913/

IzQuieRDo, M. J. Bloque temático 2: Marco teórico de la igualdad. Sistema sexo-género. Universidad Autónoma de Barcelona. Recuperado de http://www.fongdcam.org/.../genero/.../Marco_Tco_de_la_lgualdad_Sist_ sexo_genero.pdf

MAQUEDA A., M. L. (2006). La violencia de género. Entre el concepto jurídico y la realidad social. Revista Electrónica de Ciencia Penal y Criminología, (8-2), 1-13. Recuperado de http://criminet.ugr.es/recpc/08/recpc08-02.pdf

Ministerio de la Mujer y de las Poblaciones Vulnerables (MIMP). (2012). El silencio nos hace cómplices, jactuemos! Guía sobre la violencia de género para funcionarias y funcionarios del Estado. Lima: MIMP.

Movimiento Manuela Ramos. (2011). Elecciones Generales 2011. La violencia hacia las mujeres en los planes del gobierno: Análisis de las propuestas. Lima: Biblioteca Nacional del Perú.

Movimiento Manuela Ramos. (2013). Transversalidad de género. Un recorrido de conceptos y herramientas básicas. Lima.

Organización de las Naciones Unidas (ONU). (2006). Poner fin a la violencia contra la mujer. De las palabras a los hechos. Recuperado de http://www.un.org/womenwatch/daw/public/VAW_Study/VAW-Spanish.pdf

Organización Mundial de LA SALUd (OMS). (2017). Violencia contra la mujer. Recuperado de http://www.who.int/ mediacentre/factsheets/fs239/es/ 
Organización Panamericana de La Salud (OPS). (2014). Violencia contra las mujeres en América Latina y El Caribe: Análisis comparativo de datos poblacionales de 12 países. Washington, D. C.: OPS. Recuperado de http://www. paho.org/hq/index.php?option=com_content\&view=article\&id=8175\%3Aviolence-against-womenlatin-america-caribbean-comparative-analysis-population-data-from-12-countries\&catid=1505\%3Aabout-us\&i

Rico, N. (1996). Violencia de género: Un problema de derechos humanos. Recuperado de http://www.cepal.org/ mujer/noticias/paginas/3/27403/violenciadegenero.pdf 